\title{
Study on Impact of Electronic Commerce on the Development of Financial Accounting
}

\author{
Qiuye $\mathrm{Xia}^{1, \mathrm{a}}$ \\ ${ }^{1}$ Nanchang Institute of Science \& Technology, Nanchang, Jiangxi, 330108 \\ ${ }^{\mathrm{a}}$ email
}

Keywords: E-commerce, Financial Accounting, Impact Studies

\begin{abstract}
E-commerce is through the computer network of the business activities, the high-speed channel for all types of businesses to establish the exchange of information, allowing users to at a high speed, low cost, high efficiency, the momentary grasp opportunities, the first to obtain competitive conditions. As a new form of trade, the arrival of e-commerce to the development of our economy provide new opportunities through the Internet and e-commerce technology, a breakthrough time and space constraints, allowing users to conduct business anytime, anywhere, and therefore to the traditional financial accounting systems bring strong shock. This article will give a detailed analysis of the impact of e-commerce development has brought financial accounting.
\end{abstract}

\section{Introduction}

E-commerce is conducted through a network of business activities, belonging to the network for business operations and management information systems of its nature. E-commerce support including computer technology, network technology, communication technology, as the subject of e-commerce, parties to the transaction may abandon the traditional "one on one, face to face" transactions, and instead online trading model, not only greatly simplified transactions process, while promoting commercial activities carried out smoothly. In recent years, the development of e-commerce, serious impact on traditional financial accounting systems, and digital business environment also influence the decision of the accounting work environment.

\section{The E-commerce on the Financial Accounting Development}

Mainly in the main assumptions and accounting assumptions phases two aspects: First, the accounting entity belonging to a particular organization, refers to the range of activities of accounting tool provides for a summary of all the accounting elements of special space, which generally refers to business entities inner space. With the development of network technology and computer technology, more and more companies have set up Internet companies. However, these types of companies without a clear spatial extent, and no fixed form, the traditional concept of the accounting entity assumption is not clear. Second, the impact of accounting assumptions phases. E-commerce to break the traditional accounting of time, space limitations, to achieve real-time financial information, dynamic collection, dissemination and use, and thus more refined division of accounting period. This change to a certain extent simplified accounting period, in time to provide data analysis for business decision-making and management in order to facilitate appropriate responses made.

In the traditional financial accounting, historical cost principle is one of the important principles. Historical cost principle with strong objectivity, reliability and verifiability, and thus use more common. But the historical cost information under specific conditions likely to provoke criticism from different quarters, such as inflation. In the current network environment, the historical cost principle more vulnerable. First, the network enterprise management products for the financial products, such as securities, stocks, etc., there is a big change in the market price, so that the historical cost financial accounting information derived from the lack of sufficient accuracy. Secondly, the network can not determine the time of dissolution of the company. Some Internet companies usually only the presence of a relatively short time, although under these conditions, the 
point between historical cost and the liquidation of short, but this non-sustainable business model that can not be the historical cost of the cash flow information is a true reflection. Third, the historical cost is a static measurement attribute, if the company can not be combined with market conditions, the timely adjustment of the development strategy, the financial sector would be unable to provide the historical cost information as a basis for decision-making.

Financial accounting accrual is an enterprise revenues and expenses should be a relationship based on rights and responsibilities, through its duration and impact of occurrence for accounting. The current cost and income payments will not affect the case, only the cost and revenue moneys belonging to the current period to the current period as the revenues and expenses for processing. First, the impact of e-commerce accounting assumptions phases, so that the basic form is consistent with the accounting period during the transaction of its business, effectively reducing the deployment of a variety of problems occur, such as the spread of cross-distribution, so as to be more reasonable, clearly of fees and costs allocated. Secondly, the process of e-commerce, mainly in the electronic payment way payment, online real-time payment to complete the balance of payments, to ensure that its trading results will not pay for the phenomenon did not occur [1].

A document written summary financial report belong to business results and financial condition, comprising income statement of changes in equity, balance sheet and financial situation, the current flow statement, financial statements and other schedules and notes. Financial reporting mainly serve the users of corporate information, financial information requested must have a very high accuracy, and requires the ability to timely update, at any time to provide the latest financial information. The traditional manual operation in this regard would often mistakes, omissions, etc., relying on e-commerce and computer technology and network technology, automated financial reporting statements generated by computer superb computing power, effectively ensure the accuracy of financial information, help updated in real time financial information to provide timely basis for decision-making enterprise management and decision-making.

\section{To Promote the Development of E-Commerce Environment and Financial Accounting Measures}

In accordance with the fair and impartial manner, to create a good, stable and healthy environment for e-commerce, e-commerce environment to promote the development of financial accounting. First, given the appropriate legal status of electronic documents, improve network accounting legal. Secondly, the formation of relatively stable network information platform, so that enterprises with the financial statements, audit, accounting and reimbursement and other remote management capabilities, and the promotion of electronic forms of documents and money, improve the use of financial information and access methods. Finally, vigorously develop the software. Excellent network of financial software for e-commerce development has played a certain role in promoting, in order to improve service efficiency, the development of software must have online payment, remote reporting and audit, financial information online real-time query and other new features [2].

Enterprise information in the business of e-commerce environment, can automatically collect information about the internal and external accounting by the accounting system, and thus corporate accounting should provide timely information to these effective corporate management decision-making, thus contributing to the accounting and accounting oversight functions in the form of information management accountant to change: First, for the inflow and outflow of capital and outside the enterprise commodity management; second, combined with internal information systems and consumer demand, a reasonable internal cost accounting, efficient allocation of funds of enterprises and departments cost: Third, preparation of financial analysis reports, and promote the development of enterprises. With the gradual financial accounting information transparency, the rapid development of e-commerce model is bound under the impetus of the management accountant.

Sharing e-commerce accounting information resources to improve the incidence of network security incidents. And how to ensure the security of the network accounting information, effective 
measures need to be taken from the internal and external. First, the internal network to take appropriate safety measures, such as system logs, security analysis tools, firewalls, authentication systems, virtual private network, security monitoring and early warning systems. Secondly, according to the occurrence of past security incidents, establishing dynamic security management model to analyze the results of early warning response and record-healing network weaknesses, and to assess and tracking system network suspicious signs and the use of the current situation, a reliable, objective, accurate network security audit report [3].

The current business management without the support of advanced electronic information technology, which can effectively improve the economic efficiency of enterprises. Thus higher network accounting model for accounting personnel requirements. Culture of modern financial accounting personnel, not only need to strengthen the knowledge of accounting, should also be computer literate culture, communications network knowledge, WEB knowledge to develop a high-quality compound talents as the main target. Complex accounting talent is the key condition to promote enterprise, regional, national e-commerce development. Thus, accountants must continue to learn new knowledge of financial theory at work, improve their professional skills and to strengthen the network of knowledge and understanding of modern business processes. Meanwhile, enterprises should be enhanced appraisal system, improve the assessment difficulty basis of merit, and the existing accountants intensive training to enable them to quickly adapt to new working environment, to ensure that they are familiar with accounting information management and accounting under the new environment workflow and provide accurate information to support decision-making activities of enterprises, so as to promote the development of enterprises [4].

\section{Conclusion}

E-commerce as a new business model, it helps to improve the development of China's economy. Faced with the opportunities and challenges of electronic commerce, businesses are required to change the traditional financial accounting model, train a large number of complex accounting personnel, not only need to master the new e-commerce theoretical knowledge, but also need to strengthen computer technology and network technology culture, to quickly adapt to new working environment, so as to promote the development of enterprises.

\section{References}

[1] Chen Jiali. Research on Electronic Commerce Network Financial Accounting Development [J]. Enterprise Economy, 2012, 06: 128-132.

[2] Yu Ming. The Impact of E-business in the Ming on the Financial Accounting [J]. Mudanjiang University, 2012,10: 154-155.

[3] Fang Yong. Research Impact of Electronic Commerce on the Financial Accounting Development [J]. Managers, 2014, 36: 1-2.

[4] Tian Xiaomei. Study Impact of Electronic Commerce on the Financial Accounting [J]. Heilongjiang Science, 2014, 06: 232. 